\title{
Association of tumor necrosis factor $\beta$ genetic polymorphism and sepsis susceptibility
}

\author{
FRANCIELI DELONGUI ${ }^{1}$, CÍNTIA MAGALHÃES CARVALHO GRION ${ }^{2}$, \\ MARIA ANGELICA EHARA WATANABE ${ }^{3}$, HELENA KAMINAMI MORIMOTO ${ }^{1}$, \\ ANA MARIA BONAMETTI ${ }^{2}$, JULIE MASSAYO MAEDA ODA ${ }^{3}$, ANA PAULA KALLAUR ${ }^{1}$, \\ TIEMI MATSUO ${ }^{4}$ and EDNA MARIA VISSOCI REICHE ${ }^{1}$
}

\begin{abstract}
Departments of ${ }^{1}$ Pathology, Clinical Analysis and Toxicology, and ${ }^{2}$ Clinical Medicine, Health Sciences Center, University Hospital; ${ }^{3}$ Molecular Genetic Laboratory, Biological Sciences Center; ${ }^{4}$ Department of Biostatistics, Exacts Sciences Center, Londrina State University, Londrina, Paraná, Brazil
\end{abstract}

Received November 12, 2010; Accepted January 11, 2011

DOI: 10.3892/etm.2011.213

\begin{abstract}
The association of the tumor necrosis factor $\beta$ (TNF- $\beta$ ) Ncol genetic polymorphism with susceptibility to sepsis was evaluated in 60 consecutive patients diagnosed with sepsis and in 148 healthy blood donors. Genomic DNA was extracted from peripheral blood cells and a 782 base-pair fragment of the TNF- $\beta$ gene was amplified by PCR. The PCR products were subjected to Ncol restriction digestion and analysed by restriction fragment length polymorphism analysis. Tumor necrosis factor $\alpha(\mathrm{TNF}-\alpha)$ and the C-reactive protein (CRP) serum levels were also determined by ELISA and nephelometry, respectively. Among the septic patients, the allelic frequencies of TNFB1 and TNFB2 were 0.2833 and 0.7166 , respectively, and they differed from those observed in the blood donors $(p=0.0282)$. The TNFB2 allele frequency was higher in the septic patients than in the blood donors [odds ratio $=1.65$ (CI 95\% 1.02-2.69), $\mathrm{p}=0.0315$ ]. The TNF- $\alpha$ and CRP serum levels and the APACHE II and SOFA clinical scores did not differ in the patients with the TNFB1 or TNFB2 alleles $(\mathrm{p}>0.05)$. The results suggest that the TNFB2 allele is associated with susceptibility to sepsis, but it was not found to be associated with the immunological and clinical biomarkers of the disease.
\end{abstract}

\section{Introduction}

Sepsis, defined by the presence of both infection and a systemic inflammatory response, is a potent activator of the

Correspondence to: Dr Edna Maria Vissoci Reiche, Department of Pathology, Clinical Analysis and Toxicology, Health Sciences Center, Londrina State University, Av. Robert Koch, 60, CEP 86.038-440, Londrina, Paraná, Brazil

E-mail: reiche@sercomtel.com.br

Key words: Ncol genetic polymorphism, sepsis, tumor necrosis factor $\beta$, lymphotoxin- $\alpha$, biomarkers host's immune inflammatory and coagulation responses. Currently, it is regarded as the most prevalent illness among hospitalized patients and is one of the main causes of death in the non-coronary care unit (1-3). Although the general direction of activation is similar between individuals, there are very important inter-individual differences in the immune, inflammatory and coagulation responses to infection (4). In response to infectious stimuli, such as lipopolysaccharides (LPS), tumor necrosis factor $\alpha(\mathrm{TNF}-\alpha)$ is a cytokine that is released early mainly by macrophages, and it is a principal mediator of the inflammatory response to infection which stimulates acute inflammation by its action on different cells, such as endothelial cells, leukocytes, natural killer cells and hepatocytes. The biological actions of TNF- $\alpha$ depend on its concentration. Therefore, any genetic variability in the production of TNF- $\alpha$ after an infectious stimulus could have a significant impact on the degree of inflammatory response and could therefore potentially influence the clinical outcome (4).

Genetic polymorphisms with potential influences on the inflammatory response have been identified in a variety of antigen recognition pathways, as well as pro- and anti-inflammatory cytokines (4). Genetic predisposition has a substantial impact on outcome in sepsis (5), modifying both the disease process and the approach taken to therapy and is considered in the PIRO system for staging sepsis that takes into account the predisposition $(\mathrm{P})$, the insult infection (I), the response (R) and organ dysfunction (O) (3). Most of the candidate genes that could influence the intensity of the inflammatory response are located on the highly polymorphic region of human chromosome 6 , known as the major histocompatibility complex (MHC). These include genes involved in the antigen recognition pathways (HSP70-1, HSP70-2, HSP70-HOM, CD14 and toll-like receptors) and genes involved in the expression of pro-inflammatory cytokines, such as TNF- $\alpha$ and tumor necrosis factor $\beta$ (TNF- $\beta$ ) or lymphotoxin- $\alpha$ (LT- $\alpha)$ (4).

TNF- $\beta$ is a cytokine produced by T lymphocytes similar to TNF- $\alpha$, and binds to TNF receptors. It is also expressed as a membrane protein, in which one chain of the secreted form associates with two subunits of a structurally related 
membrane protein known as lymphotoxin- $\beta$ (LT- $\beta$ ). LT- $\beta$ activates endothelial cells and neutrophils and is thus a mediator of acute inflammatory response, providing a link between T-cell activation and inflammation. These biological effects of TNF- $\beta$ are the same as those of TNF- $\alpha$, consistent with their binding to the same receptors. However, as the quantity of TNF- $\beta$ is much less that the amounts of TNF- $\alpha$ made by LPS-stimulated mononuclear phagocytes, TNF- $\beta$ is not readily detected in the circulation. Therefore, TNF- $\beta$ is usually a local cytokine and not a mediator of systemic injury (6).

TNF- $\alpha$ and TNF- $\beta$ genes are located next to each other within the human leukocyte antigen (HLA) class III genes on chromosome 6 and evolutionary studies have suggested a common ancestor for both genes that duplicates during evolution (7). The role of the polymorphisms of these genes in the susceptibility of sepsis has been evaluated in different populations worldwide (8). A single nucleotide polymorphism (SNP) is also found at position +252 located in the first intron of the TNF- $\beta$ gene, and consists of a $\mathrm{G}$ in the wild-type allele, TNFB1, and an A in the variant allele, TNFB2 (9). Known as the Ncol polymorphism, it has been identified as a potentially influential locus in many inflammatory conditions. Studies carried out in German white patients with septic shock have shown that the TNFB2 allele results in a higher TNF- $\alpha$ secretory capacity than the TNFB1 allele, and that the TNFB2 allele is also associated with a greater risk of death. Among patients with post-operative severe sepsis, $65 \%$ of non-survivors and $12 \%$ of survivors were homozygous for the variant allele (TNFB2/B2) (10).

The TNFB2 variant allele was also a risk factor for the development of septic shock in multiple trauma patients (11). In these patients, the homozygous genotype for the TNFB2 variant allele was associated with severe sepsis and high serum levels of TNF- $\alpha$, and the results suggested that the TNF- $\beta$ polymorphism could be a genetic marker of another gene located in the MHC region that is associated with susceptibility to sepsis. In patients with blunt trauma, severe sepsis and increased cytokine production were diagnosed among those that presented with the homozygous genotype for the TNF- $\beta$ Ncol polymorphism, either the homozygous genotype wild-type (TNFB1/B1) or the homozygous variant allele (TNFB2/B2) (12). Among patients with communityacquired pneumonia, an association was observed between those homozygous for the variant allele (TNFB2/B2) and the development of septic shock. However, no association was observed between TNFB2/B2 and high mortality (13). However, these previous studies were carried out in populations from the Northern Hemisphere that show a homogeneous genetic structure. Few studies were carried out in the countries from the Southern Hemisphere, including Brazil, that has one of the most genetically heterogeneous populations in the world. In order to address this question, the objective of the present study was to evaluate the association of the TNF- $\beta$ Ncol genetic polymorphism with susceptibility to sepsis and its outcome in Southern Brazilian patients.

\section{Materials and methods}

Study design. The protocol was approved by the Institutional Research Ethics Committee of the State University of
Londrina and a voluntary written consent form was obtained from the individuals enrolled (or from their legal guardians).

The prospective study included 60 consecutive patients admitted to the University Hospital of Londrina between May 2007 and June 2008 with severe sepsis or septic shock, defined according to the American College of Chest Physicians/ Society of Critical Care Medicine (ACCP/SCCM) consensus conference criteria (3). The patients were included in the study at the time of sepsis diagnosis, they received standard hospital treatment as required and the clinical outcome was monitored prospectively. Age, gender, primary site of infection (determined by clinical presentation and/or positive focus cultures), the severity of the sepsis [evaluated by the Acute Physiology and Chronic Health Evaluation II (APACHE II) index] (13), and organ dysfunction [evaluated by Sequential Organ Failure Assessment (SOFA)] (14), were collected at each patient's entry into the study. The exclusion criteria were $<18$ years of age, missing informed consent forms and patients with immunosuppression of any etiology, including cancer, receiving current immunosuppressive therapy or chemotherapy, human immunodeficiency virus (HIV) infection, liver insufficiency (Child C) and severe chronic renal disease with dialysis therapy. Blood samples were collected within $24 \mathrm{~h}$ after the sepsis diagnosis. The control group comprised of 148 healthy blood donors from the same region that were attended at the Blood Bank of Londrina during the same period. Their demographic data were colleted from the records of the Regional Blood Bank of Londrina. All information and the samples used in the study were coded and patient and healthy blood donor confidentiality was preserved according to the guidelines for studies of human subjects.

Immunological assays. Prior to the analysis, peripheral venous blood was collected without anti-coagulant, centrifuged and stored at $-20^{\circ} \mathrm{C}$. TNF- $\alpha$ serum levels were determined by enzyme-linked immunosorbent assay (ELISA, Kit Human TNF- $\alpha e$ Bioscience $^{\mathrm{TM}}$, San Diego, CA, USA), with lower detection limit of $2 \mathrm{pg} / \mathrm{ml}$. The reference value was $<8.2 \mathrm{pg} /$ $\mathrm{ml}$, according the manufacturer's instructions. CRP serum levels were determined by nephelometry (Nephelometer 100 Analyser BN II ${ }^{\mathrm{TM}}$, Dade-Behring - Siemens Healthcare Diagnostics Inc., IL, USA), with a lower detection limit of $<0.175 \mathrm{mg} / \mathrm{l}$. The reference value used was $<3 \mathrm{mg} / \mathrm{l}$ according to the manufacturer's instructions.

Ncol genetic polymorphism. Genomic DNA was extracted from peripheral blood cells by a salting-out procedure (15) and 100-200 ng of DNA were used to amplify a 782-bp fragment of the TNF- $\beta$ gene, including the first intron, by polymerase chain reaction (PCR) as previously reported $(11,12)$ with some modifications. Briefly, the primers used were determined according to the GenBank no. X02911 as follows: Primer 1 (TNF1 sense) 5' CCG TGC TTC GTG CTT TGG GAC TA 3'; Primer 2 (TNF2 antisense) 5' AGA GGG GTG GAT GCT TGG GTT TC 3' (Invitrogen ${ }^{\mathrm{TM}}$, Life Technologies, Carlsbad, CA, USA). PCR was performed with a final volume of $25 \mu \mathrm{l}$, with $2.5 \mathrm{mM}$ of each primer, $50 \mathrm{mM} \mathrm{MgCl} 2,1.25 \mathrm{mM}$ dNTP (Invitrogen, Life Technologies), 1.25 units Thermus aquaticus thermostable DNA polymerase in the buffer provided (Invitrogen, Life Technologies) and $1 \mu \mathrm{l}$ of the DNA sample. 
Table I. Frequency of the tumor necrosis factor $\beta$ (TNF- $\beta$ ) Ncol genetic polymorphism in septic patients and healthy blood donors from the Southern Brazilian population.

\begin{tabular}{|c|c|c|c|c|c|}
\hline \multirow[t]{2}{*}{ Group } & \multicolumn{3}{|c|}{ TNF- $\beta$ Nco1 genotype frequency ${ }^{a}$} & \multicolumn{2}{|c|}{ Allelic frequency ${ }^{\mathrm{b}}$} \\
\hline & TNFB1/B1, n (\%) & TNFB1/B2, n (\%) & TNFB2/B2, n (\%) & TNFB1 & TNFB2 \\
\hline Patients $(n=60)$ & $7(11.7)$ & $20(33.3)$ & $33(55.0)$ & 0.2833 & 0.7166 \\
\hline Blood donors $(\mathrm{n}=148)$ & $21(14.2)$ & $75(50.7)$ & $52(35.1)$ & 0.3952 & 0.6047 \\
\hline Total $(n=208)$ & $28(13.5)$ & $95(45.7)$ & 85 (40.9) & 0.3630 & 0.6370 \\
\hline
\end{tabular}

TNFB1, allele with the restriction site of the Nco1; TNFB2, variant allele without the restriction site of the Nco1; TNFB1/B1, genotype homozygous for the allele TNFB1; TNFB1/B2, genotype heterozygous for the allele TNFB1; TNFB2/B2, genotype homozygous for the allele TNFB2; ${ }^{a} \chi^{2}$ test $=7.1356, \mathrm{p}=0.0282 ;{ }^{\mathrm{b}} \chi^{2}$ test $=4.63, \mathrm{p}=0.0315, \mathrm{OR}=1.65(95 \%$ CI $1.02-2.69)$.

PCR conditions were performed in a thermocycler (PCR Sprint-Thermo Hybaid ${ }^{\mathrm{TM}}$, Biosystems, Barcelona, Spain) and comprised of 5 min denaturation at $94^{\circ} \mathrm{C}$ for initial denaturation; 37 cycles of $45 \mathrm{sec}$ at $94^{\circ} \mathrm{C}$ for denaturation, $45 \mathrm{sec}$ at $67^{\circ} \mathrm{C}$ for the anneling and $45 \mathrm{sec}$ at $72^{\circ} \mathrm{C}$ for the elongation; and $10 \mathrm{~min}$ at $72^{\circ} \mathrm{C}$ for final elongation. In all PCR analyses, a negative control (without a DNA sample) and a positive control (with the amplified 782-bp DNA fragment) were included.

The PCR products were subjected to restriction fragment length polymorphism (RFLP) analysis as described in previous studies $(11,12)$ with some modifications. Briefly, $10 \mu \mathrm{l}$ of the PCR product were completely digested with $0.3 \mu \mathrm{l}$ of Ncol $10 \mathrm{U} / \mu \mathrm{l}$ enzyme (Invitrogen, Life Technologies) for $4 \mathrm{~h}$ at $37^{\circ} \mathrm{C}$. Following Ncol digestion, $10 \mu \mathrm{l}$ of the digested and undigested samples were electrophoresed on a $10 \%$ acrylamide gel $(100 \mathrm{~V}$, $3 \mathrm{~h}$ ), and stained with silver, as described previously (16). The TNFB1 allele includes a restriction site for Ncol which results in 196- and 586-bp fragments after digestion and the TNFB2 allele (lacking the restriction site for Ncol) which results in a fragment of $782 \mathrm{bp}$. The heterozygous genotype TNFB1/B2 results in three fragments $(782,586$ and $196 \mathrm{bp})$. The images of the gel were captured and recorded by a photodocument system and the Digi Doc-It Program version 1.1.25.

Statistical analysis. A database with the results was set up using the Excel Program of Microsoft Office and the data were statistically analysed by the Epi Info Program v.3.3.2 (17) and SAS v.8.02 (18). Descriptive results of continuous variables were expressed as the maximum and minimum values, the means \pm standard deviation $(\mathrm{SD})$, and the median or proportions with $95 \%$ confidence intervals (CI) as appropriate. Departure from Hardy-Weinberg equilibrium and differences in categorical variables were assessed by the Chi-square test or Fisher's exact test, where appropriate. The quantitative variables were evaluated by the Mann-Whitney test. The odds ratio (OR) was calculated by comparing the distributions of alleles and genotypes between healthy subjects (reference) and septic patients. Two-tailed p-values of $<0.05$ were used to indicate statistical significance.

\section{Results}

Profile of subjects studied. Of the 60 patients included, the

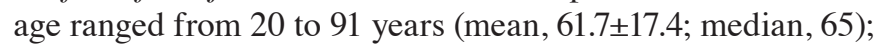

$36(60 \%)$ were male and $24(40 \%)$ were female, with a male:female ratio of 1:1.5. Of the 148 blood donors, the age ranged from 18 to 62 years (mean, 37.6 \pm 10.8 ; median, 38); $83(56.1 \%)$ were male and $65(43.9 \%)$ were female, with a male:female ratio of 1:1.28. The patients were older than the blood donors (Mann-Whitney test, $\mathrm{p}<0.0001$ ), but they did not differ from the blood donors in gender $\left(\chi^{2}\right.$ test, $\left.\mathrm{p}=0.6407\right)$. The primary sites of infection presented by the sepsis patients were the respiratory tract in 37 (61.7\%), the abdominal tract in $14(23.3 \%)$, the urinary tract in $6(10 \%)$ and the skin or soft tissue in 2 patients (3.3\%). The primary site of infection was not determined in $1(1.7 \%)$ patient. At the time of study inclusion, severe sepsis was present in $26(43.3 \%)$ patients and septic shock in 34 patients (56.7\%).

The septic patients showed higher TNF- $\alpha$ serum levels at the time of admission that ranged from $<2$ to $342.9 \mathrm{pg} / \mathrm{ml}$ (mean, 16.3 \pm 52.4 ; median, 4.6) when compared to the blood donors whose levels ranged from $<2$ to $134.5 \mathrm{pg} / \mathrm{ml}$ (mean, $6.8 \pm 13.6$; median, 3.1). However, no significant differences were found (Mann-Whitney test, $p=0.2070$ ). Increased serum levels of CRP were also detected in all of the patients with sepsis at the time of admission, and the values were significantly higher, ranging from 12.7 to $341 \mathrm{mg} / \mathrm{l}$ (mean, $152.4 \pm 86.0$; median, 145) when compared to the values obtained among the blood donors, which ranged from 0.2 to $10.4 \mathrm{mg} / \mathrm{l}$ (mean, 1.7 \pm 2.1 ; median, 0.8) (Mann-Whitney test, $\mathrm{p}<0.0001$ ).

Genotype and allele frequencies. The genotype frequencies presented by the septic patients and blood donors were significantly different (Table I), essentially a result of the TNFB2 allele frequency $\left(\chi^{2}\right.$ test $\left.=7.1356, \mathrm{p}=0.0282\right)$. Among the septic patients, 7 (11.7\%) were homozygous for the allele TNFB1 (TNFB1/B1), 20 (33.3\%) were heterozygous (TNFB1/ B2) and $33(55 \%)$ were homozygous for the allele TNFB2 (TNFB2/B2). Among the healthy donors, the heterozygous genotype was more frequent, obtained in 75 individuals (50.7\%), followed by the homozygous TNFB2/B2 detected in $52(35.1 \%)$ and TNFB1/B1 in $21(14.2 \%)$ individuals. The overall allele frequencies were 0.3630 for the TNFB1 allele and 0.6370 for the TNFB2 allele of the TNF- $\beta$ Ncol polymorphism. The allele frequency of TNFB2 for the septic patients (0.7166) was higher than that observed among the healthy individuals $(0.6047)\left[\chi^{2}\right.$ test $=4.63, p=0.0315$, OR=1.65 (CI 95\% 1.02-2.69)]. Among the 60 septic patients, severe 
Table II. Distribution of the tumor necrosis factor $\beta$ (TNF- $\beta$ ) and C reactive protein serum levels in septic patients and healthy blood donors from the Brazilian population, according to the TNF- $\beta$ genetic polymorphism.

\begin{tabular}{|c|c|c|c|}
\hline \multirow[b]{2}{*}{ Group } & \multicolumn{3}{|c|}{ TNF- $\beta$ genotype } \\
\hline & TNFB1/B1 & TNFB1/B2 & TNFB2/B2 \\
\hline Patients (n) & 7 & 20 & 33 \\
\hline \multicolumn{4}{|l|}{ TNF- $\alpha(\mathrm{pg} / \mathrm{ml})^{\mathrm{a}}$} \\
\hline Range & $2.0-51.2$ & $2.0-232.6$ & $2.0-342.9$ \\
\hline Mean \pm SD & $12.5 \pm 18.3$ & $17.4 \pm 50.9$ & $16.5 \pm 58.8$ \\
\hline Median & 4.3 & 4.4 & 5.0 \\
\hline \multicolumn{4}{|c|}{$\mathrm{C}$ reactive protein $(\mathrm{mg} / \mathrm{l})^{\mathrm{b}}$} \\
\hline Range & $83.7-308.0$ & $28.7-328.0$ & $12.7-341.0$ \\
\hline Mean \pm SD & $165.0 \pm 73.2$ & $136.9 \pm 88.2$ & $159.2 \pm 88.2$ \\
\hline Median & 153.0 & 135.0 & 153.0 \\
\hline Blood donors (n) & 21 & 75 & 52 \\
\hline \multicolumn{4}{|l|}{ TNF- $\alpha(\mathrm{pg} / \mathrm{ml})^{\mathrm{c}}$} \\
\hline Range & $2.0-134.5$ & $2.0-72.4$ & $2.0-38.4$ \\
\hline Mean \pm SD & $12.0 \pm 28.7$ & $6.1 \pm 10.7$ & $5.9 \pm 5.9$ \\
\hline Median & 3.0 & 2.6 & 4.0 \\
\hline \multicolumn{4}{|c|}{$\mathrm{C}$ reactive protein $(\mathrm{mg} / \mathrm{l})^{\mathrm{d}}$} \\
\hline Range & $0.3-6.1$ & $0.2-10.4$ & $0.2-9.8$ \\
\hline Mean \pm SD & $1.9 \pm 1.8$ & $1.7 \pm 2.2$ & $1.7 \pm 2.2$ \\
\hline Median & 1.0 & 0.8 & 0.8 \\
\hline
\end{tabular}

TNFB1, allele with the restriction site of the Nco1; NFB2, variant allele without the restriction site of the Nco1; TNFB1/B1, genotype homozygous for the allele TNFB1; TNFB1/B2, genotype heterozygous for the allele TNFB1; TNFB2/B2, genotype homozygous for the allele TNFB2;

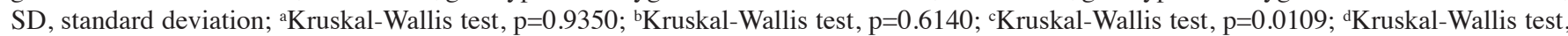
$\mathrm{p}=0.2626$.

sepsis occurred more frequently in those that presented the TNFB1 allele, diagnosed in $14(51.9 \%)$ patients. In contrast, shock septic was more frequent among those with the TNFB2 allele, detected in $21(63.6 \%)$ patients. However, no significant difference was obtained $\left(\chi^{2}=1.45, \mathrm{p}=0.2284\right)$.

Association of TNF- $\beta$ Ncol genetic polymorphism with TNF- $\alpha$, and CRP serum levels. The TNF- $\alpha$ and CRP serum levels obtained in the septic patients and in the healthy individuals, distributed according the TNF Ncol polymorphism, are shown in Table II. The median serum TNF- $\alpha$ concentrations were higher in both the septic patients and the blood donors with the homozygous genotype, TNFB2/B2, when compared to the other genotypes, TNFB1/B1 and TNFB1/B2. However, the differences were significant only for the blood donor values (Kruskal-Wallis test, $\mathrm{p}=0.9350$ and $\mathrm{p}=0.0109$, respectively). Although the CRP serum levels were also higher in the patients with the TNFB2/B2 genotype, no significant differences were obtained (Kruskal-Wallis test, $\mathrm{p}=0.6140$ ). When the TNF- $\alpha$ and CRP serum values were evaluated according to the frequency of the TNFB1 and TNFB2 alleles, no significant differences were also observed (Table III).

Association of TNF- $\beta$ Ncol genetic polymorphism with the APACHE II and SOFA scores, and mortality. The severity of illness scores and the mortality rate of sepsis distributed according to the TNF- $\beta$ Ncol alleles are shown in Table III.
The APACHE II scores ranged from 16 to 30 (median, 21) in the patients with the TNFB1/B1 genotype, from 8 to 37 (median, 26.5) in the TNFB1/B2 genotype, and from 12 to 41 (median, 22) in the TNFB2/B2 genotype. The SOFA scores ranged from 4 to 18 (median, 11) in the patients with the TNFB1/B1 genotype, from 1 to 16 (median, 9) in the TNFB1/ B2 genotype, and from 2 to 17 (median, 8) in the TNFB2/B2 genotype. Although the APACHE scores were higher among the patients that presented the heterozygous and homozygous genotypes for the TBFB2 allele when compared to those that had the homozygous TNFB1 genotype, the difference was not significant. Both the APACHE II and SOFA scores did not differ among the TNF- $\beta$ Ncol genotypes (Kruskal-Wallis test, $p=0.7461$ and $p=0.9147$, respectively). When these scores were evaluated according to the frequency of the TNFB1 and TNFB2 alleles, no significant differences were also observed (Mann-Whitney test, $\mathrm{p}=0.6989$ and $\mathrm{p}=0.7373$, respectively). Although the frequency of the TNFB2 allele was higher among the septic non-survivors compared to the survivors, the mortality rate of sepsis did not differ with respect to the TNF- $\beta$ Ncol alleles $\left(\chi^{2}\right.$ test $\left.=0.7477, \mathrm{p}=0.3872\right)$.

\section{Discussion}

Sepsis is a complex disease that arises because of the interaction of a person's genotypes with environmental influences and most of the evaluation regarding the role of different 
Table III. Tumor necrosis factor $\beta$ (TNF- $\beta$ ) and C reactive protein (CRP) serum levels, and the APACHE II and SOFA scores obtained in septic patients from the Brazilian population, according to the TNF- $\beta$ gene alleles.

\begin{tabular}{|c|c|c|c|}
\hline Immunological and clinical biomarkers & TNFB1 allele $^{f}(n=27)$ & TNFB2 allele $^{\mathrm{g}}(\mathrm{n}=33)$ & P-value \\
\hline TNF- $\alpha$ serum levels $(\mathrm{pg} / \mathrm{ml})$ & & & 0.7188 \\
\hline Range & $2.0-232.6$ & $2.0-342.9$ & \\
\hline Mean \pm SD & $16.1 \pm 44.4$ & $16.5 \pm 58.8$ & \\
\hline Median & 4.3 & 5.0 & \\
\hline CRP serum levels (mg/l) & & & $0.5622^{\mathrm{t}}$ \\
\hline Range & $28.7-328.0$ & $12.7-341.0$ & \\
\hline Mean $\pm \mathrm{SD}$ & $144.2 \pm 84.1$ & $159.2 \pm 88.2$ & \\
\hline Median & 137.0 & 153.0 & \\
\hline APACHE II & & & $0.6989^{\circ}$ \\
\hline Range & $8.0-37.0$ & $12.0-41.0$ & \\
\hline Mean \pm SD & $24.0 \pm 8.2$ & $23.7 \pm 7.9$ & \\
\hline Median & 25.0 & 22.0 & \\
\hline SOFA & & & 0.7373 \\
\hline Range & $1.0-18.0$ & $2.0-17.0$ & \\
\hline Mean $\pm \mathrm{SD}$ & $9.1 \pm 4.3$ & $8.6 \pm 4.0$ & \\
\hline Median & 9.0 & 8.0 & \\
\hline Survivors (\%) & $7(25.9)$ & $12(36.4)$ & 0.3872 \\
\hline Non-survivors (\%) & $20(74.1)$ & $21(63.6)$ & \\
\hline
\end{tabular}

TNFB1, allele with the restriction site of the Nco1; TNFB2, variant allele without the restriction site of the Nco1; SD, standard deviation; APACHE, Acute Physiology and Chronic Health Evaluation II; SOFA, Sequential Organ Failure Assessment; a Mann-Whitney test, 0.1296, $\mathrm{p}=0.7188$; ${ }^{\mathrm{b}}$ Mann-Whitney test, $0.3359, \mathrm{p}=0.5622$; ${ }^{\mathrm{C}}$ Mann-Whitney test, $0.1496, \mathrm{p}=0.6989$; ${ }^{\mathrm{d}}$ Mann-Whitney test, $0.1125, \mathrm{p}=0.7373 ;{ }^{\mathrm{e}} \chi^{2}$ test, $0.7477, \mathrm{p}=0.3872$; ${ }^{\mathrm{H}}$ Heterozygous and homozygous for the TNFB1 allele; ${ }^{\mathrm{g}}$ Homozygous for the TNFB2 allele.

genotypes in sepsis is gene association studies $(5,19)$. The demographic and clinical characteristics of the septic patients enrolled in this study were in accordance with other reports $(11,20-22)$, such as the increased number of elderly and male patients. Also, the main source of sepsis, the respiratory tract, followed by the abdominal, urinary tract and skin or soft tissue, were also in accordance with previous studies $(21,23)$.

The overall frequencies of the TNFB1 and TNFB2 alleles obtained were similar to previous studies carried out in populations from Northern Hemisphere countries $(11,12)$. The present study found that the frequency of the TNFB2 allele was significantly higher among septic patients and that this allele possesses a significant association with the development of sepsis compared to the TNFB1 allele.

Although the small number of TNFB1 homozygous patients with sepsis enrolled in the present study makes the association less accurate, with lower OR compared to previous studies, the results obtained are in accordance with a certain study (11), where individuals with the homozygous genotype for the TNFB2 allele showed a significant risk for the development of severe sepsis (OR=5.2, 95\% CI 1.52-17.95) after adjustment for age and trauma severity. Another study (12) confirmed that individuals with the homozygous genotype for the TNFB2 allele presented a high risk for sepsis $(\mathrm{OR}=11.0$, 95\% CI 1.7-66.7) when compared to heterozygous individuals.

The OR values found in the previous reports, caused by the higher frequency of the homozygosity for the TNFB2 allele compared to the frequency obtained in the present study, can be explained by the same factors, including the difference in the methods that were used to analyse the RFPL products. While the previous studies used agarose gel electrophoresis to evaluate the fragments obtained after the Ncol digestion, in the present study, we used acrylamide gel electrophoresis, which presents an increased sensitivity in differentiating samples with inconclusive results obtained using agarose gels, and can facilitate the analysis of fragments with $192 \mathrm{bp}$. The higher frequency of the heterozygous genotype obtained could also be explained by the heterogeneous ethnic structure of the Brazilian population, that has been formed by the Southern and Mediterranean Europeans (Portuguese, Italian and Middle Eastern populations), Asians, Arabians, Africans and Native Amerindians since the 16th century (22).

As expected, all the patients presented increased CRP serum levels, higher than the discriminatory values of $50 \mathrm{mg} / 1$ suggested for patients in intensive care $(25,26)$, confirming the usefulness of this biomarker of systemic inflammation in identifying patients with sepsis. The CRP and TNF- $\alpha$ serum levels from all the individuals evaluated showed that the wide range in their values could result from the different microorganisms that were isolated from the septic patients (data not shown) and the genetic heterogeneity of the inflammatory response (4). In addition to environmental factors that trigger cytokine secretion (27), in vitro studies have identified that individuals can demonstrate consistent differences in leukocyte cytokine secretion (28) and that these differences are probably genetically pre-determined (27). 
Inter-individual variability in the CRP serum levels has also been described in previous studies $(29,30)$. A certain study demonstrated that $2.9 \%$ of the total variation in circulating CRP levels could be explained by two haplotypes among eight SNPs, genotypes of the CRP gene (31), conferring the different secretion of this phase acute protein. Moreover, the precise location of the genetic elements controlling the TNF- $\alpha$ response remains unclear (12). The production and response of TNF- $\alpha$ are partly regulated at the transcription level and the role of many SNPs in the promoter region of TNF- $\alpha$ and in the TNF- $\beta$ gene in the determination of the inflammatory disease susceptibility or as a marker of severity has been the subject of certain studies $(9,10)$. Regarding the TNF- $\beta$ polymorphism, the TNFB2 allele has been found to be a stronger transcriptional activator than the TNFB1 allele, resulting in higher TNF- $\alpha$ level.

The TNF- $\alpha$ and TNF- $\beta$ genes are tightly linked and only 1,240 bases separate the polyadenylation site of TNF- $\beta$ and the transcription start site of TNF- $\alpha$ (32). Considering that the TNF- $\alpha$ and TNF- $\beta$ genes are in the same transcriptional orientation, and that the TNF- $\alpha$ promoter is located in the conserved non-conding sequences within the intergenic regions of these two genes, a mechanism for the specific and efficient transcription of the TNF- $\alpha$ gene has been described (33). The intrachromosomal interactions formed by the TNF- $\alpha$ gene promoter and two distal enhancers could promote the formation of a simple loop that brings the 5' promoter and $3^{\prime}$ termination sequence of a single active gene into close proximity.

The TNF- $\alpha$ serum levels are increased in patients with septic shock and are correlated with clinical outcome (10). However, because of its short half-life (34), the value of TNF- $\alpha$ as a marker of susceptibility or severity for sepsis is limited.

The present study enrolling Brazilian individuals found an association between the TNFB2 allele and the occurrence of sepsis, but failed to demonstrate a significant association in baseline TNF- $\alpha$ serum levels between the TNFB2 and TNFB1 carriers. This apparent discrepancy could be explained by certain factors. Firstly, the delay between the beginning of sepsis and septic shock and the timing of the blood sample collection. Animal and human studies have previously shown that the peak of serum TNF- $\alpha$ production occurs during the first hour after the infectious stimulus. Evaluating serial blood samples, it has been demonstrated that the peak of TNF- $\alpha$ at the first day of sepsis was $58 \mathrm{pg} / \mathrm{ml}$, and this progressively decreased to $27 \mathrm{pg} / \mathrm{ml} 3$ days later (35). Probably, the best time to evaluate the intravascular secretion of TNF- $\alpha$ was missed in the present study. Secondly, the serum levels of TNF- $\alpha$ do not represent the concentration of this cytokine locally produced at the site of infection (36-38). Thirdly, the detectable serum levels of TNF- $\alpha$ do not take into account the membrane-bound form of TNF- $\alpha$, which is up-regulated in many cells, including endothelial cells and leukocytes of patients with multiple organ failure (39). Fourthly, the nature of the microorganism and primary sites of infection can influence the kinetics and the extent of serum TNF- $\alpha$ levels, making these data difficult to compare to previous studies $(40,41)$.

A study on TNF- $\alpha$ and IL-1 $\beta$ cytokines that are synthesized at the beginning of the inflammatory cascade has rendered different results. A significantly increased serum level of
TNF- $\alpha$ and IL-1 $\beta$ has been demonstrated in newborns with sepsis (42). However, the results of different published studies are contradictory. Certain studies found the diagnostic value of TNF- $\alpha(43,44)$, while others demonstrated similar or even lower levels in infected compared to healthy newborns $(45,46)$.

Discrepancies in results among studies can also be explained by the variation in laboratory methods in performing the analysis, the time of the sample collection or the control population selected (47). Other factors can also account for the discrepant results presented by different studies. Besides the relative small study population in the present and previous studies on the relation of TNF locus polymorphisms to sepsis susceptibility or mortality, differences in the distribution of HLA class II alleles based on ethnic distribution of the study populations can also influence the results. In the present study, the heterogeneity of the septic patient population was presented in certain characteristics, such as age, the different primary site of infection, the microorganisms isolated from their biological samples and the severity of the disease. The stimulus required to develop sepsis could be determined genetically, but couldd be modified by other factors, such as pathogen virulence and comorbid illnesses.

Previous studies have reported that the TNF- $\beta$ Ncol polymorphism was associated with mortality $(10,20)$. A certain study (48) demonstrated that patients with the heterozygous TNFB1/B2 genotype had a 1.6-fold higher relative risk for developing post-operative infectious complications. If patients with the homozygous TNFB2 genotype developed a complication, they had a 1.5-fold higher risk for severe complications, and the patients with post-operative sepsis who were homozygous for the TNFB2 genotype had significantly elevated mortality.

In the present study, although patients with the TNFB2 allele were more frequent among those who developed septic shock, and this suggests a genetic predisposition for sepsis severity, the similar frequencies of the TNFB2 allele that were observed in the patients with severe sepsis and septic shock, and in the survivors and non-survivors are in accordance with previous studies $(20,49)$. This result is consistent with the hypothesis that the TNFB2 allele cannot by itself be responsible for the difference in the severity of the disease. In Caucasian adult septic shock patients, the timing of adequate antibiotic therapy was a greater determinant and independent predictor of mortality than the TNF- $\alpha-308$ promoter, the TNF- $\beta$ Ncol and the IL-10-1082 promoter polymorphisms (49).

Other SNPs in the genes involved in the inflammatory and anti-inflammatory response could act in synergism with the TNF- $\beta$ Ncol polymorphism contributing to the imbalance of the immune response and, consequently, to the occurrence and/or outcome of sepsis, including the IL-1 $\beta(50,51)$, IL-1ra $(51,52)$, IL-6 (53), TLR4 +896 and TNF- $\alpha-308$ (54), and IL-10 polymorphisms (50). After adjustment for age, ethnicity, gender, burn size and inhalation injury, variant alleles at TNF- $\alpha$ 308A, TLR4, IL-6 and CD14 were significantly associated with an increased risk for severe sepsis (54).

The cross-sectional approach that was used in this study could not definitively address whether the TNF- $\beta$ Ncol polymorphism can influence the severity of sepsis. This preliminary study should be extended to a prospective longitudinal study enrolling a great number of patients in order to contribute to 
the better comprehension of the role of the TNF- $\beta$ genotypes in the development of sepsis. The possibility of identifying a genetic biomarker that can be used to detect patients with a high risk of sepsis and septic shock early in the disease course could influence the treatment of the disease. These high risk patients could benefit with early and aggressive therapeutic strategies that consider the individual genotype, including intervention anti-TNF therapies.

\section{Acknowledgements}

This study was supported by grants from the Coordination for the Improvement of Higher Level or Education Personnel (CAPES) of Brazilian Ministry of Education; the Institutional Program for Scientific Initiation Scholarship (PIBIC) of the National Council for Scientific and Technological Development (CNPq), and the State University of Londrina (PROPPG).

\section{References}

1. Angus DC, Linde-Zwirble WT, Lidicker J, Clermont G, Carcillo J and Pinsky MR: Epidemiology of severe sepsis in the United States: analysis of incidence, outcome, and associated costs of care. Crit Care Med 29: 1303-1310, 2001.

2. Brun-Buisson C, Doyon F, Carlet J, et al: Incidence, risk factors, and outcome of severe sepsis study in intensive care units. A multicenter prospective study in intensive care units. JAMA 274 968-974, 1995.

3. Levy MM, Fink MP, Marshall JC, et al: 2001 SCCM/ESICM/ ACCP/ATS/SIS International Sepsis Definitions Conference. Crit Care Med 31: 1250-1256, 2003.

4. Waterer GW and Wunderink RG: Science review: genetic variability in the systematic inflammatory response. Crit Care 7: 308-314, 2003

5. Sorensen TI, Nielsenm GG, Andersen PK and Teasdale TW: Genetic and environmental influences on premature death in adult adoptees. N Engl J Med 318: 727-732, 1988.

6. Eigler A, Sinha B, Hartmann G and Endres S: Taming TNF: strategies to restrain this proinflammatory cy tokine. Immunology Today 18: 487-492, 1997.

7. Zhang D-L, Li J-S, Jiang Z-W, Yu B-J, Tang X-M and Zheng H-M: Association of two polymorphism of tumor necrosis factor gene with acute biliary pancreatitis. World J Gastroenterol 9: 824-828, 2003.

8. Holmes CL, Russell JA and Walley KR: Genetic polymorphisms in sepse and septic shock-role in prognosis and potencial for therapy. Chest 124: 1103-1115, 2003.

9. Messer G, Spengler U, Jung MC, et al: Polymorphic structure of the tumor necrosis factor (TNF) locus: an Ncol polymorphism in the first intron of the human TNF-beta gene correlates with a variant amino acid in position 26 and a reduced level of TNF-beta production. J Exp Med 173: 209-219, 1991.

10. Stuber F, Petersen M, Bokelmann F and Schade U: A genomic polymorphism within the tumor necrosis factor locus influences plasma tumor necrosis factor- $\alpha$ concentrations and outcome of patients with severe sepsis. Crit Care Med 24: 381-384, 1996.

11. Majetschak M, Flohé S, Obertacke U, et al: Relation of a TNF gene polymorphism to severe sepsis in trauma patients. Ann Surg 203: 207-214, 1999.

12. Majetschak M, Obertacke U, Schade FU, et al: Tumor necrosis factor gene polymorphisms, leukocyte function, and sepsis susceptibility in blunt trauma patients. Clin Diagn Lab Immunol 9: 1205-1211, 2002.

13. Knaus WA, Zimmermann JE, Wagner DP, Draper EA and Laurence DE: APACHE - acute physiology and chronic health evaluation: a physiologically based classification system. Crit Care Med 9: 591-597, 1981.

14. Ferreira FL, Bota DP, Bross A, Mélt C and Vincent JL: Serial evaluation of the SOFA score to predict outcome in critically ill patients. JAMA 286: 1754-1758, 2001.

15. Miller AS, Dykes DD and Polesky HS: A simple salting out procedure for extraction DNA from human nucleated cells. Nucleic Acid Res 16: 1215-1219, 1988.
16. Reiche EMV, Bonametti AM, Watanabe MAE, et al: Sociodemographic and epidemiological characteristics associated with human immunodeficiency virus type 1 (HIV-1) infection in HIV-1-exposed but uninfected individuals, and in HIV-1infected patients from a southern Brazilian population. Rev Inst Med Trop Sao Paulo 47: 239-246, 2005.

17. Dean AG, Dean JA, Coulombier D, Brendel KA, Smith DC and Burton H: Epi Info, Version 6: a Word-Processing Database, and Statistics Program for Public Health on IBM-Compatible Microcomputers. Centers for Disease Control and Prevention, Atlanta, GA, USA, 1995.

18. SAS Institute Inc.: SAS/STAT User's Guide, Version 6. Fourth Edition. SAS Institute Inc, Cary, NC, 1989.

19. Sutherland AM and Russell JA: Issues with polymorphism analysis in sepsis. Clin Infect Dis 41: S396-S402, 2005.

20. Waterer GW, Quasney MW, Cantor RM, et al: Septic shock and respiratory failure in community-acquired pneumonia have different TNF polymorphism associations. Am J Respir Crit Care Med 163: 1599-1604, 2001.

21. Degoricija V, Sharma M, Legac A, Gradiser M, Sefer S and Vucicevic Z: Survival analysis of 314 episodes of sepsis in medical intensive care unit in University Hospital: impact of intensive care unit performance and antimicrobial therapy. Croat Med J 47: 385-397, 2006.

22. Brun-Buisson C, Meshaka P, Pinton P and Vallet B; EPISEPSIS Study Group: EPISEPSIS: a reappraisal of the epidemiology and outcome of severe sepsis in French intensive care units. Intensive Care Med 30: 580-588, 2004.

23. Esteban A, Frutos-Vivar F, Ferguson ND, et al: Sepsis incidence and outcome: contrasting the intensive care unit with the hospital ward. Crit Care Med 35: 1284-1289, 2007.

24. Mikawa AY, Tagliavini SA and Costa PI: CCR5 genotype and plasma $\beta$-chemokine concentration of Brazilian HIV-infected individuals. Braz J Med Biol Res 35: 1333-1337, 2002.

25. Ribeiro MA: Levels of C-reactive protein in serum samples from healthy children and adults in São Paulo, Brazil. Braz J Med Biol Res 30: 1055-1059, 1997.

26. Povoa P, Almeida E, Moreira P, et al: C-reactive protein as an indicator of sepsis. Intensive Care Med 24: 1052-1056, 1998.

27. Westendorp RGJ, Langermans JAM, Huizinga TWJ, Verweij CL and Sturk A: Genetic influence on cytokine production and fatal meningococcal disease. Lancet 349: 170-173, 1997.

28. Van der Linden MW, Huizinga TW, Stoeken DJ, Sturk A and Westerndorp RG: Determination of tumor necrosis factor-alpha and interleukin-10 production in a whole blood stimulation system: assessment of laboratory error and individual variation. J Immunol Methods 218: 63-71, 1998.

29. Yan M, Zhao L, Zheng F, Sun X, Zhang Y and Wang C: The relationship between gene polymorphism and CRP level in a Chinese Han population. Biochem Genet 45: 1-9, 2007.

30. Danik JS and Ridker PM: Genetic determinants of C-reactive protein. Curr Atheroscler Rep 9: 195-203, 2007.

31. Martinez-Calatrava MJ, González-Sanches JL Martinez-Larrad MT, Pérez-Barba M and Serrano-Ríos M: Common haplotypes of the C-reactive protein gene and circulating leptin levels influence the interindividual variability in serum C-reactive protein levels. The Segovia study. Thromb Haemost 98: 1088-1095, 2007.

32. Posch PE, Cruz I, Bradshaw D and Medhekar BA: Novel polymorphisms and the definition of promoter alleles of the tumor necrosis factor and lymphotoxin $\alpha$ loci: inclusion in HLA haplotypes. Genes and Immunity 4: 547-558, 2003.

33. Tsytsykova AV, Rajsbaum R, Falvo JV, Ligeiro F, Neely SR and Goldfeld AE: Activation-dependent intrachromosomal interactions formed by the TNF gene promoter and two distal enhancers. PNAS 23: 16850-16855, 2007.

34. Kaufmann P, Tilz GP, Lueger A and Demel U: Elevated plasma levels of soluble tumor necrosis factor receptor (sTNFp60) reflect severity of acute pancreatitis. Intensive Care Med 23: 841-848, 2007.

35. Dhainaut JF, Vincent JL, Richard C, et al: CDP571, a humanized antibody to human tumor necrosis factor-alpha: safety, pharmacokinetics, immune response, and influence of the antibody on cytokine concentrations in patients with septic shock. CPD571 Sepsis Study Group. Crit Care Med 23: 1461-1469, 1995

36. Aggarval BB and Natarajan K: Tumor necrosis factors: developments during the last decade. Eur Cytokine Netw 7: 93-124, 1996. 
37. Keel M, Ercknauer E, Stocker R, et al: Different pattern of local and systemic release of proinflammatory and anti-inflammatory mediators in severely injured patients with chest trauma. J Trauma 40: 907-912, 1996.

38. Andrejko KM and Deutschman CS: Acute-phase gene expression correlates with intrahepatic tumor necrosis factor alpha abundance but not with plasma tumor necrosis factor concentrations during sepsis/systemic inflammatory response syndrome in the rat. Crit Care Med 24: 1947-1952, 1996.

39. Pellegrini JD, Puyana JC, Lapchak PH, Kodys $\mathrm{K}$ and Millergraziano CL: A membrane TNF-alpha/TNFR ratio correlates to MODS score and mortality. Shock 6: 389-396, 1996.

40. Bagby GJ, Plessala KL, Wilson LA, Thompson JJ and Nelson S: Divergent efficiency of antibody to tumor necrosis factor- $\alpha$ intravascular and peritonitis model of sepsis. J Infect Dis 163: 83-88, 1991.

41. Wakabayashi G, Gelfand JA, Jung WK, Connoly RJ, Burke JF and Dinarello CA: Staphylococcus epidermidis induces complement activation, tumor necrosis factor and interleukin-1, a shock-like state and tissue injury in rabbits without endotoxemia: comparison to Escherichia coli. J Clin Invest 87: 1925-1935, 1991.

42. Kurt AN, Aygun AD, Godekmerdn A, Kurt A, Dogan Y and Yilmaz E: Serum IL-1 $\beta$, IL-6, IL-8, and TNF- $\alpha$ levels in early diagnosis and management of neonatal sepsis. Mediators Inflamm 31397, 2007. Doi:10.1155/2007/31379.

43. Bont ES, Martens A, van Raan J, Samson G, Fetter WP, Okken A and de Leij LH: Tumor necrosis factor- $\alpha$, interleukin- $\beta$, and interleukin-6 plasma levels in neonatal sepsis. Pediatr Res 33: 380-383, 1993

44. Ozdemir A, Oygur N, Gultekin M, Coskun M and Yegin O: Neonatal tumor necrosis factor, interleukin- $1 \alpha$, interleukin-1 $\beta$, and interleukin- 6 response to infection. Am J Perinatol 11: 282-285, 1994

45. Miller LC, Isa S, LoPreste G, Schaller JG and Dinarello CA: Neonatal interleukin-1 $\beta$, interleukin-6, and tumor necrosis factor: cord blood levels and cellular production. J Pediatr 117: 961-965, 1990
46. Edgar JDM, Wilson DC and McMillan SA: Predictive value of soluble immunological mediators in neonatal infection. Clin Sci 87: 165-171, 1994.

47. Santana Reyes C, García-Muñoz F, Reyes D, González G, Dominguez $C$ and Domenech E: Role of cytokines (interleukin1beta, 6,8 , tumour necrosis factor-alpha, and soluble receptor of interleukin-2) and C-reactive protein in the diagnosis of neonatal sepsis. Acta Paediatr 92: 221-227, 2003.

48. Kahlke V, Schafmayer C, Schniewind B, Seegert D, Schreiber S and Schröder J: Are postoperative complications genetically determined by TNF- $\beta$ NcoI gene polymorphism? Surgery 135: 365-373, 2004.

49. Garnacho-Montero J, Aldabo-Pallas T, Garnacho-Montero C, Cayuela A, Jiménez R, Barroso S and Ortiz-Leyba C: Timing of adequate antibiotic therapy is a greater determinant of outcome that are TNF and IL-10 polymorphisms in patients with sepsis. Crit Care 10: R111, 2006.

50. Turner DM, Williams DM, Sankaran D, Lazarus M, Sinnott PJ and Hutchinson IV: An investigation of polymorphism in the interleukin-10 gene promoter. Eur J Immunogenet 24: 1-8, 1997.

51. Fang XM, Schroder S, Hoeft A and Stuber F: Comparison of two polymorphisms of the interleukin-1 gene family: interleukin-1 receptor antagonist polymorphism contributes to susceptibility to severe sepsis. Crit Care Med 27: 1330-1334, 1999.

52. Danis VA, Millington M, Hyland VJ and Grennan D: Cytokine production by normal human monocytes: inter-subject variation and relationship to an IL-1 receptor antagonist (IL-1Ra) gene polymorphism. Clin Exp Immunol 99: 303-310, 1995.

53. Fishman D, Faulds G, Jeffery R, Mohamed-Ali V, Yudkin JS Humphries S and Woo P: The effect of novel polymorphism in the interleukin-6 (IL-6) gene on IL-6 transcription and plasma IL-6 levels, and as association with systemic-onset juveline chronic arthritis. J Clin Invest 102: 1369-1376, 1998.

54. Barber RF, Chang LY, Arnoldo BD, Purdue GF, Hunt JL, Horton JW and Aragaki CC: Innate immunity SNPs are associated with risk for severe sepsis after burn injury. Clin Med Res 4: 250-255, 2006. 